\title{
Assessment of the Time for Vessel's Readiness to Sail in Ice Conditions
}

\author{
Anisimov A.N., Razvozov S.Yu., Menshikov V.I.
}

\begin{abstract}
It is shown that the preparation of the exploration for the swimming management of the ice and the process of such impact should be carried out with the external supply of demand of the company, the captain of the merchant and the crew on the information, leaving allowing the convenience of operating the external with due The level of related safety element of the ves-sel's degree of and so is the procurement and cargo of it on board, with the associated enforced element of protection to link the environment. The task of assessing the readiness of the vessel for safe navigation in ice conditions under the operating or restored elements of the ship's tech-nical equipment by the method of replacing with back-up elements is considered and an analyt-ical expression is proposed technical and ship readiness for safe ice sailing, taking into account the structure of the maintenance complex, reliability and reliability of the monitoring results. It is shown that the proposed procedure to assess readiness.
\end{abstract}

Keywords : technical means, vessel, reliability, ice sailing conditions, safety of ice sailing, inspection time.

\section{INTRODUCTION}

The International Maritime Organization (IMO) has adopted the International Code for Vessel Navigation in Polar Waters (Polar Code, (IPC)) and related amendments to make it mandatory under both the International Convention for the Safety of Life at Sea (SOLAS) and the International Convention on the Prevention of Pollu-tion from Ships (MARPOL).развивающейся The provisions of the Polar Code related to the SOLAS 74/78 International Con-vention were adopted at the 94th session of the IMO Maritime Safety Committee (MSC) in November 2014 [1]. At the same time, the environmental provisions related to the implementation of the provisions of the MARPOL International Convention were adopted at the 68th session of the Marine Environment Protection Committee (MEPC) in May 2015. The requirements of the Code entered into force on January 01, 2017.элементов Moreover, the purpose of the code is to ensure the safe operation of vessels and the protection of polar environment from the risks inherent in polar waters.

For each vessel to which the Polar Code applies, a Manual for Operation in Polar Waters (MOPV) shall be developed, which shall also include the following operations [1]:зависимости

Revised Manuscript Received on October 15, 2019.

* Correspondence Author

Anisimov A.N., Admiral Makarov State University of Maritime and Inland Shipping, 198035, Russia, Saint-Petersburg, Dvin-skaya st., 5/7.

Razvozov S.Yu., Admiral Makarov State University of Maritime and Inland Shipping, 198035, Russia, Saint-Petersburg, Dvin-skaya st., 5/7.

Menshikov V.I., Admiral Makarov State University of Maritime and Inland Shipping, 198035, Russia, Saint-Petersburg, Dvin-skaya st., 5/7.
- voyage planning - in order to avoid a vessel sailing in ice conditions that go beyond the design operational ca-pabilities or restrictions imposed on a vessel:

- obtaining environmental forecasts;

- implementation of special measures aimed at maintaining the operability of equipment and systems at low temperatures, icing of the upper structures of the vessel, as well as the presence of sea ice:

- requests from the authorities providing emergency assistance;

- carrying out measures to assist in situations that go beyond the operational capabilities of the vessel.

The vessel preparation for sailing in ice and the planning of such a voyage are carried out with an aim of providing the shipping company, the master and crew with information that allows for the vessel operation with due regard for the safety of both the vessel itself and the people on board, observing environmental protec-tion requirements [2]. Ice sailing is always associated with the danger of damage to the hull and possible delays in the way due to a number of unforeseen situations.уходящие Therefore, before the voyage starts, the vessel shall under-go appropriate training, which includes the following activities.торговых

Dock survey, including inspection of the underwater part of the hull, rudder, propellers, bottom fittings in the dock.только At the same time, special attention during inspection is given to the stem, the helical steering group and the area of variable waterline along the entire hull as the area most affected by iсе.системы If possible, the screws are re-placed with steel screws with removable blades.установление According to the survey results, if necessary, it is carried out cleaning, painting and repair of the underwater part of the vessel's hull. A dock survey for vessels operating in the northern conditions is carried out annually. It is also inspected the technical condition of the steering wheel, propellers, propeller shaft, especially in the area where it adjoins the deadwood, inspection of kingston grilles.розничной

Bottom and side kingstones shall be provided for ice sailing vessels.разделении If an onboard kingston is clogged with ice, a bottom kingston is used. When sailing in ice conditions in shallow water, the bottom kingston may become clogged with silt. In this case, an onboard kingston is used.прибыли Thermal insulation of the fire line passing along the open deck.

After using it at low temperatures, it is necessary to drain the water from the fire line, opening the drain valves, in order to avoid rupture of pipelines.представляют Inspection and repair of the internal volumes of the vessel's hull, including a set of waterproof bulkheads, sheathing of the 
sides and double bottom in cargo holds, inspection of drainage facilities, pressure testing of pipelines, cleaning of bilges and grids of receivers of the drainage pipeline, as well as inspection of measuring and air pipes.конечный

Preparation of deck mechanisms for sailing at low temperatures, fresh and salt water highways located on the upper decks, and warming of all the mechanisms and devices whose operation is not necessary and is associated with the danger of defrosting.

\section{PROBLEM STATEMENT}

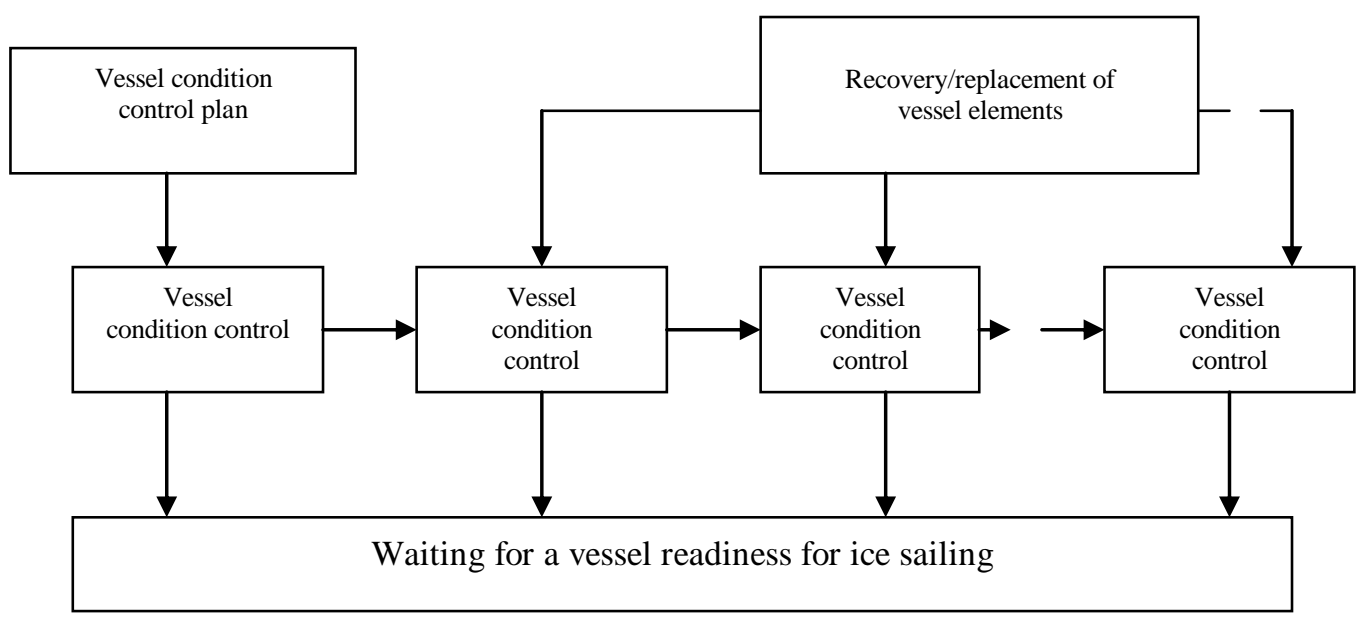

Figure 1. The structure of the vessel condition control with a subsequent assessment of its readiness for sailing in ice conditions

Estimates of the safety of vessel's sailing in ice conditions and safe operation of the vessel technical systems (TS) are widely used for the restoration of faulty systems by replacing them. At the same time, one of the main requirements for the control and recovery process is to provide preparation for a given time t3.[3 ]

Let us consider the basic principles of assessing the vessel's readiness for sailing in ice conditions and its technical means, restored by replacement. Let further control technical condition of the vessel. If the vessel is deemed unsuitable for sailing in ice in at least one parameter, then it should not be allowed being operated. In-stead of defective technical means, a spare means or parts of this means is taken. The restored technical means are monitored and, if necessary, rejected. The process of monitoring and replacing the vessel technical means continues until a positive result is obtained, that is, until the vessel is recognized as suitable for sailing in ice con-ditions [4].

Let the probability that the vessel as a whole, according to the control results, is found fit for sailing in ice conditions, and equal to $\mathrm{P} 0 \mathrm{M}$, and the vessel assessment time equal to the time of its inspection $\operatorname{t\Pi }\{0)$. At the same time, the probability of opposite event, consisting in the fact that the vessel will be deemed unsuitable for sailing in ice conditions is [5]:

$$
P_{0}^{\left(\Gamma^{*}\right)}=1-P_{0}^{(\Gamma)} \text {. }
$$

This event leads to a series of sequential situations, each of which depends on previous events. Thus, the possibility of a complex event, consisting in the fact that the vessel will be deemed unusable, and the spare technical means will be deemed fit, or the marine technical means will be restored as a result of the first replacement in other words, is equal to [6]:

$$
P_{2}^{(2)}=P_{0}^{\left(\mathrm{r}^{*}\right)} P_{3}^{(2)}
$$

where $P_{3}^{(2)}$ probability of obtaining "suitable" result when controlling a spare technical means.

In this situation, the time of vessel preparation for sailing in ice conditions can be estimated as

$$
t_{2}^{(1)}=t_{n}^{(0)}+t_{c}^{(0)}+t_{y 1}^{(3)}+t_{n 1}{ }^{(3)},
$$

where $t_{c}^{(0)}$ - time for removal of the rejected ship technical means; $t_{y 1}{ }^{(3)}+t_{n 1}{ }^{(3)}$ - the of installation on the vessel and inspection of the first technical means, respectively.

First spare vessel technical means with probability

$$
P_{3}^{\left(2^{*}\right)}=1-P_{2}^{(2)}
$$

may be deemed unfit for sailing in ice conditions. At the same time, the probability of an even more complicated event, consisting in the fact that the main technical means and the first technical reserve means may be deemed unsuitable, and the second reserve technical means are suitable, is equal to

$$
P_{2}^{(2)}=P_{0}^{\left(2^{*}\right)} P_{3}^{\left(2^{*}\right)} P_{3}^{(2)}
$$

Then the time of vessel preparation for sailing in ice conditions can be estimated as

$$
t_{2}^{(2)}=t_{2}^{(1)}+t_{c 1}{ }^{(3)}+t_{y 2}{ }^{(3)}+t_{n 2}{ }^{(3)},
$$

где $t_{c 1}{ }^{(3)}$ - time for removal of the rejected ship technical means; $t_{y 2}{ }^{(3)}, t_{n 2}{ }^{(3)}$ - time of installation on the vessel and inspection of the first technical means, respectively.

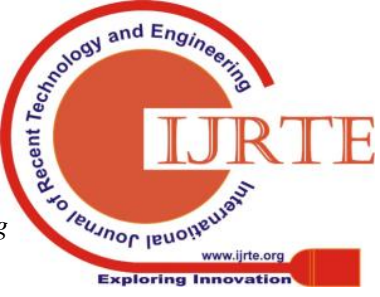




\section{SOLUTION METHOD}

Let us find the probability of vessel readiness by induction for the case of $n$ successive replacements

$P_{n}^{(2)}=P_{0}^{\left(2^{*}\right)}\left[P_{3}^{\left(2^{*}\right)}\right]^{n-1} P_{3}^{(2)}$

and the time of vessel's readiness to sail in ice conditions with $n$ replacements

$t_{2}^{(n)}=t_{n}{ }^{(0)}+t_{c}{ }^{(0)}+\sum t_{i=1} t_{i=1}^{n-1}+\sum t_{y i}{ }_{i=1}^{\left({ }^{(3)}\right.}+\sum t_{n i}{ }_{i=1}^{\left({ }^{3}\right)}$

where $t_{c i}{ }^{(3)}, t_{y i}{ }^{(3)}, t_{n i}{ }^{(3)}$ - time of removal, installation and verification of the $i$-th technical means, respectively.

With $n \rightarrow \infty$, the situations considered form a complete group of events

$$
P_{0}^{(2)}+\sum_{n=1}^{\infty} P_{n}^{(2)}=1 .
$$

Therefore, the probability that the vessel in time $t \leq t_{3}$ will be recognized as suitable for sailing in ice conditions on the basis of the formula of full probability [5], [7], when its condition is restored by replacing the vessel technical means, is

$P_{2}=P_{0}^{(2)} P_{20}+\sum_{n=1}^{\infty} P_{n}^{(2)} P_{2 n}$

where $P_{20}=. P\left(t_{2}^{(0)} \leq t_{3}\right)$ - probability that the time for assessing the vessel's readiness is less than the specified one; $P_{2 n}=P\left(t_{2}^{(n)} \leq t_{3}\right)$ - a likelihood that the vessel's readiness at $n$ replacements will not exceed the specified one.

Probability of vessel's recognition as suitable for ice sailing as a result of $N$ replacements of technical means is equal to

$P_{2}(N)=P_{0}^{(2)} P_{20}+\sum P_{n}^{(2)} P_{2 n}$.

With an absolutely reliable control system, the probabilities appear in formulas (1), (3) and (4)

$P_{0}^{(2)}=P_{u}, P_{0}^{\left(2^{*}\right)}=1-P_{u}, P_{3}^{(2)}=P_{u}^{(3)}, P_{3}^{\left(2^{*}\right)}=1-P_{u}^{(3)}$

Where $P_{u}, P_{u}^{(3)}$ - probabilities of the working condition of the technical means and the spare technical means, respectively, which are the features of reliability of these means.

When the control is carried out with errors and serviceable technical means can be falsely rejected and, conversely, when serviceable means can be erroneously classified as serviceable. Let the share of falsely rejected technical means in their entire mass, which came under control, is equal to the probability $P_{л о}$, and the share of faulty, but recognized as serviceable systems, also considered in the entire set of controlled technical means, is equal to the probability $P_{н о}$. Then [8]

$$
P_{0}{ }^{(2)}=P_{u}+P_{л о}+P_{н о}, P_{3}^{(2)}=P_{u}^{(3)}-P_{л о}{ }^{(3)}+P_{н о}{ }^{(3)}
$$

With perfect control accuracy, probability (3) makes sense of the probability that the vessel in time $t \leq t_{3}$ will be ready for ice sailing, and with inaccurate control - a likelihood that it will be recognized as such during this time that it is not the same.

Likelihood that the vessel as a result $N$ replacements of technical means will be really ready for sailing in ice conditions

$$
P_{z u}(N)=P_{0}^{(2)} P_{z 0} P_{u / 2}+\sum P_{u}^{(2)} P_{z u} P_{u / 2}^{(3)}
$$

where $P_{u / 2}, P_{u z}{ }^{(3)}$ - probabilities of the operational condition of the technical means and the spare technical means, respectively, provided that they were recognized as ensuring safety during ice sailing under control.

Probability (7) can be used as an indicator of the effectiveness of assessment of the vessel's readiness for ice sailing.

Obviously, the described procedure of assessment of the vessel's readiness for ice sailing consists of homogeneous operations, the execution time of which can be taken as mutually independent values. Moreover, the mathematical expectation and time dispersion (2) are equal to:

$$
\begin{array}{r}
m_{t 2}(n)=m_{t n}(0)+m_{t c}(0)+(n-1) m_{t c}(3)+n\left(m(3)+m_{t n}(3)\right), \\
\sigma_{t 2}^{2}(n)=\sigma_{t n}^{2}(0)+\sigma_{t c}^{2}(0)+(n-1) \sigma_{t c}^{2}(3) \\
+n\left(\sigma_{t y}^{2}(3)+\sigma_{t n}^{2}(3)\right),
\end{array}
$$

The law of distribution of time intervals for inspection of technical means $t_{t n}(0)$ will be considered exponential. However, the inspection time may include, in addition to the time required directly for the control of technical means, the time for preparatory work, such as connecting, warming up, setting up control means. An even larger number of terms has preparation time $t_{2}(n)$ at replacements.

As a result and based on the central limit theorem [5], the law of time distribution (2) can be considered normal. This assumption becomes more and more valid with an increase in the number of substitutions. $n$. Under normal law, the probability that $t_{2}(n) \leq t_{3}$, is determined by the formula [5] [9]:

$P_{2 n}=\left[\Phi\left(\left(t_{3}-m_{t 2}(n)\right) / \sigma_{t 2}(n)\right]+0.5\right.$.

\section{DISCUSSION OF THE RESULT}

Let the deviation values $\Delta X=X-x_{H}$ of parameter $X$ from nominal value $x_{u}$ in the technical means responsible for the safety of ice sailing of the vessel are distributed according to the normal law with a standard deviation equal to $\sigma_{\Delta x x}=5$ conventional units and mathematic expectation equal to $m_{\Delta x}$ $=0$. In order to ensure the safety of ice sailing, this parameter has a bilateral tolerance $\sigma_{\Delta x x}=7.5$ conditional units. While $\mathrm{P}_{и}$ $=0$,87. Measurement error values $\Delta X_{u}$ are distributed according to normal law with $\sigma_{\Delta x \mathrm{x}, \mathrm{u}}=4$ conditional units and $m_{\Delta x, u}=0$. The deviations of the parameter of the spare technical means are also distributed according to the normal law with $\sigma_{\Delta x x}=4$ conditional units and $m_{\Delta x}=0$, which corresponds to $P_{\text {и }}^{(3)}=0,94$. 
The timing of the operation to verify and restore the technical means and the reserve technical means is subject to normal laws with $m_{t n}(0)=40$ conditional units. $m_{t n}(0)=15$ conditional units, $\sigma_{t n}(0)=10$ conditional units, $\sigma_{t n}(3)=3$ conditional units. The time of removal of an unreliable technical means and the installation of reserve technical means is almost zero. It is required to determine the probability of preparing the vessel for safe sailing in ice conditions over time $t_{2} \leq 80$ conditional units.

For the given initial data on the distribution of values of the output parameter and the error of its measurement using the results [9], one can find

$$
P_{л о}=0,035 ; P_{н о}=0,021 ; P_{л о}{ }^{(3)}=0,027 ; P_{н о}{ }^{(3)}=0,013,
$$

and determine under the formula (5) that $P_{0}{ }^{(2)}=0,856$ и $P_{3}^{(2)}$ $=0,926$.

The value of probabilities (1) and $P_{2 n}$, calculated by expressions (8) and(9), and readiness indicators (4) are given in Table 1. In this table, the denominator shows for comparison the probability values calculated for the case of perfect control, i.e. at $P_{л о}=P_{н о}=P_{л о}{ }^{(3)}=P_{н о}{ }^{\left({ }^{(3)}\right.}=0$.

Table 1.

\begin{tabular}{|c|c|c|c|c|c|}
\hline No. & 0 & 1 & 2 & 3 & 4 \\
& & & & & \\
\hline$P_{n}^{(2)}$ & 0.856 & 0.133 & 0.0099 & 0.0007 & 0.00005 \\
& 0.87 & 0.122 & 0.0073 & 0.0004 & 0.00003 \\
\hline$P_{2 n}$ & 0.9999 & 0.993 & 0.834 & 0.316 & 0.029 \\
\hline$P_{2}(N)$ & 0.856 & 0.988 & 0.9966 & 0.99679 & 0.996791 \\
& 0.87 & 0.991 & 0.9974 & 0.99752 & 0.997521 \\
\hline
\end{tabular}

\section{SUMMARY AND CONCLUSION}

The considered methodology for assessing the time of vessel's readiness for ice sailing by the control method with the subsequent restoration of its ability to sail in ice conditions by replacing an unreliable vessel technical means takes into account the structure of the setof maintenance operations, the features of the reliability of such means and the reliability of the results of control operation.

Based on this assessment of the vessel's readiness for safe ice sailing, a distribution of the possible duration of the set of control actions for the inspection of the vessel and its application with the known features of the measuring control means and the specified maintenance rule can be found.

\section{REFERENCES}

1. Guidance on the application of the provisions of the International Code for Vessels Operated in Polar Waters (Polar Code). ND. No. 2 - 030101 031. Russian Maritime Register of Shipping. St. Petersburg. 2017. 26 p.

2. Verzakov G. F., Kinsht V.N., Rabinovich V.I., Timonen L.S. Introduction to technical diagnostics. Energiya, 1968.

3. Novotarsky V.A., Staroselets V.G. About an algorithm for optimizing the synthesis of complex systems. Automation and Telemechanics, No. 1, pp. 144-154, 1972.

4. Petrov V.I. The majority-gradient method for solving the problem of optimizing the sequential performance control procedure. ATI No. 2 , 1970, P. $129-136$

5. Gnedenko B.V., The course of probability theory. M.: Nauka, 1969.

6. Buslenko N.P. Modeling of complex systems / N.P. Buslenko. - M.: Nauka, 1978. - $400 \mathrm{p}$
7. Wentzel E. S., Operations research. M.: Sov. Radio, 1972. Organization of management processes. Under the total ed. mad eby G. Kh. Popova. M. Ekonomika, 1975.

8. Ivanov V.M. The solution of the problem of optimal use of the fleet with limitation on gross productivity / V.M. Ivanov, V.I. Kozhukhar // Articles / GIIVT. - Gorky, 1982. - Issue 190. - P. 28-35.

9. Apatin E.F. To the issue of formulation and solution of multicriteria transport type problems / E.F. Apatin, V.K. Kalachev. // Problems of river transport: collection of scientific articles. / GIIVT. - Gorky, 1980. - P. $61-62$. 